(C) The Author(s), 2022. Published by Cambridge University Press. This is an Open Access article, distributed under the terms of the Creative Commons Attribution licence (http://creativecommons.org/licenses/by/4.0/), which permits unrestricted re-use, distribution and reproduction, provided the original article is properly cited. 0361-6843/22

\title{
GROUNDING UNLAWFUL DISCRIMINATION
}

\author{
Michael P. Foran \\ University of Strathclyde, Glasgow, Scotland
}

\begin{abstract}
This article explores the necessary and jointly sufficient conditions for the recognition of a ground of unlawful discrimination. It is important not only to have a coherent understanding of the currently enumerated grounds, but also to have a theoretical framework that can assist in enumerating new grounds through the open-ended "other status" aspect of many legal frameworks. To that end, this article argues that personal characteristics that are generally morally irrelevant, and that are socially salient in that they carry with them a prevalence of inequality-laden attitudes, amount to necessary and jointly sufficient conditions for recognizing a ground of unlawful discrimination. Other conditions, such as immutability and the presence of relative group disadvantage, will be assessed and dismissed as contingent but not necessary conditions.
\end{abstract}

Why is it that sex and race and religion are protected grounds for the purposes of antidiscrimination law, but height or hair color are not? Is it just as wrongful to discriminate against someone on the basis of their physical appearance as it is to do so on the basis of their philosophical beliefs? Even if it is, should the state approach each of these forms of discrimination similarly? These questions, or questions like them, must be answered before a coherent theoretical account of discrimination law can be advanced.

Over the last few decades, the legal prohibition of certain forms of wrongful discrimination has become more and more prevalent. Most liberaldemocratic states, either through a constitutional or a statutory framework, have developed their own antidiscrimination models that are often informed by international human rights obligations. These international human rights treaties usually contain some provision for the prohibition of wrongful discrimination or protection of the equal moral status of persons, for example, Article 14 of the European Convention on Human Rights (ECHR) and Article 2(1) of the International Covenant on Civil and Political Rights (ICCPR). In the UK context, wrongful discrimination 
is prohibited primarily through the Equality Act $2010 .{ }^{1}$ However, it is telling that, while there is now a vast array of domestic and international antidiscrimination provisions, there is still no universally accepted definition of discrimination. ${ }^{2}$ Indeed, most frameworks simply provide a nonexhaustive list of protected grounds on which less favorable treatment is prohibited. ${ }^{3}$ This list is usually accompanied by a general inclusion of "other status" as a placeholder for grounds yet to be enumerated through the adjudicative process. How one is to determine the necessary and sufficient features of a ground of discrimination is left unaddressed.

Beyond those grounds that have traditionally been recognized in law, courts and legislators have been beset by increasing demands to expand the current list of protected grounds to include personal characteristics such as parental or marital status, ${ }^{4}$ political affiliation, ${ }^{5}$ physical appearance, ${ }^{6}$ weight, ${ }^{7}$ and even genetic identity. ${ }^{8}$ The result has been what Fiss terms a "proliferation of the protectorate." 9 Without guidance that can assist judges in their determinations, grounds have a tendency to remain confined to the list enumerated explicitly within those treaties and statutes.

A significant amount of normative work to justify the legal prohibition of wrongful discrimination is done by the grounds on which specific instances of discrimination occur. Khaitan refers to this as "grounds sensitivity" and argues that "[a]ny theory of discrimination law must account for this ground sensitivity generally, and explain the basis on which the protected grounds are selected." 10 The goal of this article is to explore why certain grounds are protected and other potential grounds are not. To that end, the task is to identify those features that are common to the existing enumerated grounds such that we might better understand the purpose of

1. Although there is an argument to be made that the common law also offers protection against wrongful discrimination at the hands of the state. Colm O'Cinneide, Equality: A Core Common Law Principle, or 'Mere' Rationality?, in Common Law Constitutional Rights 167 (Mark Elliott \& Kirsty Hughes eds., 2020); Jeffrey Jowell, Is Equality a Constitutional Principle?, 7 Current Legal Probs. 1 (1994); T.R.S. Allan, Constitutional Justice: A Liberal Theory of the Rule of LaW (2001), at 5, 8; T.R.S. Allan, Law, Liberty, and Justice: The Legal Foundations of British Constitutionalism (1993), at 7.

2. See Wouter Vandenhole, Non-discrimination and Equality in the View of the UN Human Rights Treaty Bodies (2005), at 33.

3. See Janneke Gerards, The Discrimination Grounds of Article 14 of the European Convention on Human Rights, 13 Hum. RTs. L. Rev. 99 (2013).

4. Sharona Hoffman, The Importance of Immutability in Employment Discrimination Law, 52 WM. \& Mary L. Rev. 1483, 1483-1546, 1531-1537 (2011).

5. Hoffman, supra note 4.

6. Robert C. Post et al., Prejudicial Appearances: The Logic of American Antidiscrimination LAW (2001).

7. Elizabeth Kristen, Addressing the Problem of Weight Discrimination in Employment, 90 CaL. L. Rev. 57 (2002).

8. Anita Silvers \& Michael Stein, An Equality Paradigm for Preventing Genetic Discrimination, 55 VAND. L. REv. 1341 (2002).

9. Owen M. Fiss, The Fate of an Idea Whose Time Has Come: Anti-Discrimination Law in the Second Decade After Brown v. Board of Education, 41 U. ChI. L. Rev. 742, 748 (1974).

10. Tarunabh Khaitan, A Theory of Discrimination Law (2015), at 88. 
antidiscrimination law generally and be in a position to provide a coherent framework for the development of new grounds through the adjudicative process. Of course, it could be the case that there is no unified explanation for why particular grounds are protected and others are not. ${ }^{11}$ We could simply state that the existing grounds are protected because legislatures and states chose to protect them. This analysis corresponds with a strain of thought that views discrimination law as lacking any coherent normative foundation at all. ${ }^{12}$ Ultimately that could be an explanation. However, it would be an impoverished one. There is likely a reason why states have chosen to prohibit discrimination on the basis of certain grounds and not others. Before we conclude that there is nothing that can act as a central thread in this area, it is worth giving some thought to the alternative.

It is impossible to completely separate analysis of the grounds of discrimination from other aspects of the legal framework necessary for duties of this kind to be effective. These include questions relating to why unlawful discrimination is wrongful, why the law typically applies to certain dutybearers and not others, and why certain instances of wrongful discrimination are not prohibited by law. This article does not purport to provide a comprehensive analysis of these related questions, its focus being confined to explaining why certain grounds are protected and others are not. Nevertheless, determining why it is that we protect the grounds that we do may shed some light on these issues.

\section{DISCRIMINATION: THE CONCEPT}

Discrimination is often presented in a moralized sense such that it carries with it a negative connotation of some kind, to be contrasted with a morally neutral conception. ${ }^{13}$ As Hellman notes, "to call something 'discrimination' is to criticize it, to assert that it is wrong." ${ }^{14}$ How and why discrimination is wrongful can be explained by reference to any number of values, including equality, ${ }^{15}$

11. See Patrick Shin, Is There a Unitary Concept of Discrimination?, in Philosophical Foundations of Discrimination Law 163 (Deborah Hellman \& Sophia Moreau eds., 2013).

12. See George Rutherglen, Concrete or Abstract Conceptions of Discrimination, in PHILOsoPHICAL Foundations of Discrimination LaW 115 (Deborah Hellman \& Sophia Moreau eds., 2013).

13. See Kasper Lippert-Rasmussen, The Badness of Discrimination, 9 Ethical Theory \& Moral Prac. 167, 167-168 (2006); Kasper Lippert-Rasmussen, Born Free and Equal: A Philosophical InQUiRY into the NATURE OF Discrimination (2013), at 1-2.

14. Deborah Hellman, When Is Discrimination Wrong? (2011), at 2.

15. See Sandra Fredman, Discrimination Law (2d ed. 2011); Bob Hepple, The Aims of Equality Law, 61 Current Legal Probs. 1 (2008); Bob Hepple, Equality: The Legal Framework (2d ed. 2014); Sandra Fredman, Breaking the Mold: Equality as a Proactive Duty, 60 Aм. J. Compar. L. 265 (2012); Sandra Fredman, Substantive Equality Revisited, 14 InT'L J. Const. L. 712 (2016); see also Hellman, supra note 14; Deborah Hellman, Equality and Unconstitutional Discrimination, in Philosophical Foundations of Discrimination Law 51 (Deborah Hellman \& Sophia Moreau eds., 2013). 
liberty, ${ }^{16}$ and social inclusion. ${ }^{17}$ It is not unusual for theoretical frameworks exploring discrimination to focus on one or more of these values to explain not just what makes discrimination wrongful when it is wrongful but also to explain what it is as a concept, given that the concept is conceived in moral terms. $^{18}$

However, there is an alternative approach to conceptualizing discrimination that begins from the position that it is a distinct form of action, defined not by its moral wickedness, but by what is done in the act of discriminating. For example, Benjamin Eidelson defines discrimination as follows:

To discriminate against $\mathrm{X}$, one must treat $\mathrm{X}$ less favourably than one does or would treat $\mathrm{Y}$ on the basis of property $\mathrm{P} .{ }^{19}$

In this form, discrimination remains morally neutral. Thus, we can describe discriminating taste as virtuous without contradiction. ${ }^{20}$ Discrimination is necessarily responsive to differences along some dimension. As Eidelson notes, "one can discriminate on the basis of religion, or on the basis of eye colour, and so on, but one cannot discriminate on no basis at all."21 An essential feature of discrimination, even in its morally neutral form, is thus its "ground sensitivity." ${ }^{22}$ To have discriminating taste in wine, I must pick and choose; I must pass over some and seek out others on the basis of quality. To discriminate, one necessarily compares, and one does so on the basis of some ground or property.

Thus, discrimination is simply a form of action that has just as much capacity to be virtuous as it does to be wicked. Discrimination may be impermissible for any number of reasons ranging from the disrespectful attitude that is expressed, ${ }^{23}$ to the subordination that it engenders, ${ }^{24}$ to pure consequentialist considerations of harm. But pointing to instances where acts of discrimination might be wrongful does not tell us much about when and why they are legally prohibited when they are. Legal frameworks generally

16. See Khaitan, supra note 10; Hugh Collins \& Tarunabh Khaitan, Indirect Discrimination Law: Controversies and Critical Questions, in Foundations of Indirect Discrimination LaW 1 (Hugh Collins \& Tarunabh Khaitan eds., 2018); Tarunabh Khaitan \& Sandy Steel, Wrongs, Group Disadvantage and the Legitimacy of Indirect Discrimination Law, in FoundaTIONS OF INDIRECT Discrimination Law 197 (Hugh Collins \& Tarunabh Khaitan eds., 2018); see also Sophia Moreau, What Is Discrimination?, 38 Phil. \& Pub. Afrs. 143 (2010); Sophia Moreau, Discrimination as Negligence, 40 CAN. J. PHIL. 123 (2010); Sophia Moreau, In Defense of a Liberty-Based Account of Discrimination, in Philosophical Foundations of Discrimination Law 71 (Deborah Hellman \& Sophia Moreau eds., 2013).

17. Hugh Collins, Discrimination, Equality and Social Inclusion, 66 Mod. L. Rev. 16 (2003).

18. On the different conceptions of discrimination, see Deborah Hellman, Two Concepts of Discrimination, 102 VA. L. Rev. 895 (2016).

19. Benjamin Eidelson, Discrimination and DisRespect (2015), at 17.

20. John Gardner, On the Grounds of Her Sex(uality), 18 Oxford J. Legal Stud. 167, 167 (1998).

21. Eidelson, supra note 19, at 15-16.

22. KHAITAN, supra note 10 , at 88 .

23. EIDELSON, supra note 19.

24. Sophia Moreau, Faces of Inequality: A Theory of Wrongful Discrimination (2020). 
are not concerned with abstract moral questions relating to wrongful acts in all contexts. There is usually some feature in addition to the act being morally wrongful that justifies legal intervention to prevent it. Ground sensitivity is not only an essential feature of discrimination qua discrimination, it is also essential to our understanding of legally prohibited discrimination because, within current legal frameworks, the permissibility or impermissibility of an act of discrimination turns primarily on the ground on which it has occurred. ${ }^{25}$

Indeed, it is this focus that caused the birth of indirect discrimination. ${ }^{26}$ The concept of indirect discrimination arises as a result of a grounds-oriented account of discrimination, where the ground in question is essential to determining whether the act of discrimination is legally impermissible. The reason why certain forms of height discrimination are legally impermissible is because of the relationship that they share with a ground of discrimination that is protected generally: sex. ${ }^{27}$ But height is not itself a protected characteristic and so height discrimination is not independently unlawful. This tells us something very important about legal conceptions of discrimination: often discrimination on the basis of particular grounds or on the basis of other grounds that have a sufficiently cogent connection to those particular grounds is prohibited simply by virtue of the fact that this discrimination occurred on the basis of those grounds. ${ }^{28}$ If the grounds of an act of discrimination were not essential to its legal prohibition it would not be necessary to establish any connection at all between, for example, height and sex. All that would matter would be whether this instance of height discrimination was wrongful because it was irrational or disproportionate or because it produced harmful consequences that warranted legal intervention. ${ }^{29}$

Private law frameworks do not leave much room for such nuanced analysis of the wrong-making features of particular forms of discrimination, although there may be some scope within public law. ${ }^{30}$ Usually, all that matters is whether a duty-bearer treated a rights-bearer less favorably on the basis of a particular ground. If the connection between the act and the ground is established directly then there is generally no justification that can be offered to avoid legal liability, subject to very narrowly tailored exceptions. If the discrimination occurs on the basis of some other ground then a connection must be established between that ground and the protected

25. The choice of duty-bearer is also of prime importance and will be addressed below.

26. Indeed, Eidelson argues that there is no such thing as indirect discrimination for exactly this reason. EIDELSON, supra note 19, at 2.

27. See Elisa Holmes, Anti-Discrimination Rights Without Equality, 68 Mod. L. Rev. 175, 190-191 (2005).

28. There is also the additional requirement that the discrimination must be done by a dutybearer and against a right-bearer. This will be addressed below.

29. On the inadequacy of focusing purely on rationality, see Gardner, supra note 20, at $168-169$.

30. See supra note 1. 
grounds before liability can be established, and even then, the law leaves open a question of justification. ${ }^{31}$

Importantly, many of the features that inform the legal protection of certain grounds and not others also become salient when deciding on the exceptions to the prohibition of discrimination on the basis of protected grounds. This will become clearer as the article develops. What matters at this point is that there is a distinction between the reasons why certain grounds are protected and the reasons why specific instances of discrimination, even on those grounds, may be morally permissible or impermissible. For example, race may be a protected characteristic because it is immutable or because it is morally irrelevant, but race discrimination could be prohibited when it is prohibited because those instances of discrimination contribute to the economic or social subordination of ethnic minorities. It is important to be aware of the possibility that the reasons to protect a ground may diverge from the reasons to prohibit discrimination based on that ground in certain contexts and not others. It is not unlawful for a customer to refuse to shop at a black-owned business, even if it is wrongful.

However, while this distinction is relevant, it is often the case that exceptions to the general prohibition on certain forms of discrimination are justified by reference to the reasons we protect certain grounds and not others. So, if we conclude that grounds must generally be morally irrelevant before they are protected, instances where the ground becomes morally relevant might warrant an exception to the general prohibition on discrimination. Similarly, although race is generally protected in employment contexts, it could be permissible for an employer to refuse to hire a white actor to play a black character. The best way to begin to explain this is to be clear that the reasons motivating the recognition of race as a ground may be different from the reasons to protect race in a particular context and not others.

\section{THE NECESSARY FEATURES OF A GROUND OF DISCRIMINATION}

Before we go any further, we must set out clearly what we mean when we speak of a "ground." As Khaitan notes, understood broadly, a ground for an action is simply the reason on which that action was taken. ${ }^{32}$ Thus, for example, infidelity is a ground for divorce. However, a ground should not be confused with a motive. It is entirely possible that disadvantageous treatment is based on or grounded in sex or race even if it is not motivated by animus or discriminatory intent. ${ }^{33}$ Some jurisdictions have required that

31. Although some have argued that the distinction between direct and indirect discrimination is not so stark. Sandra Fredman, Direct and Indirect Discrimination: Is There Still a Divide?, in Foundations of Indirect Discrimination LaW 31 (Hugh Collins \& Tarunabh Khaitan eds., 2018).

32. KHAITAN, supra note 10, at 29.

33. Gill and Coote v. El Vinos Co [1983] QB 425; see also John Gardner, Liberals and Unlawful Discrimination, 9 OXFord J. Legal STUd. 1, 4 (1989). 
discrimination, in addition to being grounded in or based on a prohibited ground, be motivated by discriminatory intent or some form of animus toward the victim. ${ }^{34}$

In the United Kingdom, there has been some support for a subjective account of discrimination that establishes a ground of treatment by reference to the conscious or subconscious intention of the potential discriminator. ${ }^{35}$ However, another approach identifies the grounds of a provision, criterion, or practice by reference to objective causal standards such as a "but-for" test. As Lord Goff notes, "cases of discrimination . . . can be considered by asking the simple question: would the complainant have received the same treatment ... but for his or her sex?" 36 This approach is intended to avoid "complicated questions relating to concepts such as intention, motive, reason or purpose." ${ }^{37}$ Thus, on this account, if someone is treated less favorably than another on the basis of sex, it is irrelevant that such treatment was motivated by benign "chivalry" or "courtesy." ${ }^{38}$ Similarly, Hellman argues that a policy of refusing to hire women between the ages of twenty and forty may be based on relevant considerations relating to the financial costs to the business that are entailed by a female employee becoming pregnant and not in any way be motivated by animus toward women. ${ }^{39}$ Nevertheless, she stresses that this (arguably) benign intention should not insulate the employer from moral criticism. ${ }^{40}$ In this sense, the ground of a decision can be distinguished from the motivation behind it. Still, while our focus is on the grounds for discrimination and not the motive behind such discrimination, it is necessary to narrow our focus further; not every ground for disadvantageous treatment will be protected at law.

\section{A. Personal Characteristic}

Our first step in identifying the necessary features of the existing grounds of discrimination is to narrow our focus from all possible grounds for disadvantageous treatment to personal grounds. ${ }^{41}$ By this I mean characteristics that persons have, such as race, sex, height, religious or other belief, sexual orientation, academic or professional qualification, age, disability, eye color,

34. For example, in the United States, courts have held that discriminatory motive, intention, or purpose is necessary to establish direct discrimination, at least for the purposes of the Fourteenth Amendment. See Washington v. Davis, 426 U.S. 229, 240 (1976); Pers. Adm'r of Mass. v. Feeney, 442 U.S. 256 (1979); Mobile v. Bolen, 446 U.S. 55 (1980); McCleskey v. Kemp, 481 U.S. 279 (1987). This is significant given that the court has not recognized the prohibition of indirect discrimination under the equal protection clause.

35. See in particular the approach taken by Lord Nicholls in Constable of W. Yorkshire Police v. Khan [2001] UKHL 48 [29]; Nagarajan v. London Reg'l Transp. [2000] 1 AC 501, 511-512.

36. James v. Eastleigh Borough Council [1990] 2 AC 751, 744; see also Bull v. Hall [2013] UKSC 73.

37. James v. Eastleigh Borough Council [1990] 2 AC 751, 744.

38. Gardner, supra note 33, at 4.

39. Hellman, supra note 14, at 6 .

40. Id. at 6 .

41. See Khaitan, supra note 10, at 27-30. 
parental status, wealth, occupation, and so on. A characteristic need not be immutable or "natural" for it to be personal. Thus, we can say that some personal characteristics of Emma include her perseverance, her curly hair, her occupation as a dressmaker, her status as a millionaire, and her belief that the earth is flat. A characteristic is personal if it pertains to or can assist in describing people, as opposed to things, states of mind, weather patterns, and so on.

It is by distinguishing on the basis of personal characteristics that we can identify groups of persons. The general populace can be divided into groups based on an almost infinite number of personal characteristics, from skin color, to occupation, to political affiliation, to the ownership of a specific brand and make of vehicle. It is in light of this that Khaitan draws a distinction between viewing a ground in its universal order and viewing it in its particular order. ${ }^{42}$ Thus, in the universal order, "grounds apply to all individuals." 43 In the particular order, specific "instances of a universal ground attach to different people." 44 For example, sex is a universal order ground that all individuals have and maleness is a particular order instance of sex. When we distinguish on the basis of a personal characteristic such that people are divided into groups, we do so on the basis of particular order instances of universal order personal characteristics.

A decision made on the basis of irrelevant grounds may be arbitrary without being unlawfully discriminatory for our purposes. Disadvantageous treatment afforded on the basis of the weather or some other irrelevant consideration may be unreasonable and arbitrary, but it would not engage the concerns that typically motivate the legal prohibition of wrongful discrimination, even if it might amount to wrongful conduct. The grounds for discriminatory treatment must be personal characteristics that victims of discrimination have, that they are presumed to have, or that persons they are associated with have. ${ }^{45}$ Furthermore, while the personal characteristic condition is a necessary feature of a ground of discrimination, this is clearly not sufficient: not all instances of disadvantageous treatment based on a personal characteristic are prohibited as wrongfully discriminatory. Additional criteria are necessary to further narrow the range of grounds such that we have identified those grounds that constitute protected characteristics under existing law. A number of candidate criteria have emerged over the last half century including immutability, relative group disadvantage, social salience, and moral irrelevance. Each of these will be analyzed in turn, leading to the conclusion that the necessary

42. Id. at 29-30.

43. Id. at 29 .

44. Id. at 29 .

45. See Case C-303/06, Coleman v. Attridge Law [2007] IRLR 88; Hainsworth v. Ministry of Defence [2014] EWCA (Civ) 763; Lee v. Ashers Baking Co. Ltd. [2018] UKSC 49; Equality Act 2010, Explanatory Notes 59 (UK). 
features of a ground of discrimination include social salience and moral irrelevance but not immutability or relative group disadvantage.

\section{B. Social Salience}

Lippert-Rasmussen has suggested that it is the social salience of particular personal characteristics that explains why some are protected and others are not. To him, if you are wronged because of your actual or perceived membership within a socially salient group then you have been discriminated against. ${ }^{46}$ On this account, social salience is defined as follows:

A group is socially salient if perceived membership of it is important to the structure of social interactions across a wide range of social contexts. ${ }^{47}$

Lippert-Rasmussen argues that this focus on social salience allows us to explain why it is discriminatory to differentiate on the basis of sex or race but not on the basis of other personal characteristics such as eye color or the number of vowels in one's name, while also allowing us to maintain the legitimacy of meritocratic hiring policies. ${ }^{48}$ He stresses that "idiosyncrasies" such as a refusal to hire persons with green eyes may still be morally impermissible and may even be as bad as, and reflect as corrupt a character as, "genuinely discriminatory acts." 49 However, they do not amount to discrimination because eye color and name composition are not socially salient personal characteristics.

Interestingly, Lippert-Rasmussen does not account for this difference by reference to the distinction between acts of wrongful discrimination that are lawful and acts that are not, such that the pertinent question remains why certain forms of discrimination are prohibited while others are permitted. Rather, to him, distinctions on the basis of irrelevant personal characteristics that are not socially salient "in the great majority of cases ... will not seriously harm the disadvantaged party, precisely because of their idiosyncratic nature." ${ }^{50}$ However, it is hard to see how idiosyncratic acts can be "as bad as" wrongfully discriminatory acts if what distinguishes them, aside from the social salience of the ground in question, is the fact that idiosyncratic acts do not harm their victims seriously. It is at least plausible that the arbitrary denial of employment opportunities on the basis of one's hair color still amounts to a serious harm, even if it is not independently justiciable outside of the context of constitutional and administrative law. ${ }^{51}$

46. Lippert-RASMussen, supra note 13, at 30-36; see also Lippert-Rasmussen, supra note 13; Harriet E. Baber, Gender Conscious, 18 J. Applied Phil. 53 (2001).

47. LipPert-Rasmussen, supra note 13, at 30; see also Baber, supra note 46.

48. Lippert-Rasmussen, supra note 13, at 30-31; Lippert-Rasmussen, supra note 13, at 169. Cf. David Wasserman, Discrimination, Concept of, 1 in ENCYClopedia of ApPliEd ETHICs 805, 807 (Ruth Chadwick ed., 1998); Matt Cavanagh, Against Equality of Opportunity (2002), at 156.

49. Lippert-Rasmussen, supra note 13, at 169.

50. Id. at 169 .

51. See Associated Provincial Picture Houses Ltd v. Wednesbury Corp. [1948] 1 KB 223. 
In addition, despite his claim to the contrary, it is clear that Lippert-Rasmussen is relying on a moralized conception of discrimination, one that grounds the concept of discrimination in the harm caused by the act since one distinction between discrimination and mere idiosyncrasies is that one is more seriously harmful than the other. While he has certainly captured one form of discrimination, it would be more accurate and useful to differentiate between these two examples by reference to the distinction between legally prohibited discrimination and legally permissible discrimination.

Nevertheless, there is much of value to be found in this account. Leaving aside these "idiosyncratic" acts, what precisely does Lippert-Rasmussen mean when he refers to traits that are important to the structure of social interactions? He emphasizes that this criterion operates on two scalar dimensions:

1. perceived membership within a particular social group may be more or less important in the structure of social interactions and;

2. it may be important in more or fewer social contexts while nevertheless qualifying as socially salient. ${ }^{52}$

This raises the question, how are we to decide what traits are sufficiently important to social interactions such that they might be classed as socially salient? Lippert-Rasmussen does not do much to elaborate on this, although he does note that, to do so, "one would have to say something about the individuation of social contexts and about the sorts of structuring of these that are relevant for present purposes." 53 Furthermore, he argues that "while it is somewhat unclear when a group is socially salient, this is not a flaw with the formula. The contours of our concept of discrimination are somewhat fuzzy." 54

One difficulty that we could have with this idea of importance to social interactions is that it does not appear to be much more illuminating than the term "social salience" that it is attempting to describe. This is not to say that Lippert-Rasmussen is relying on a circular definition; but it doesn't seem to be that much more precise than social salience such that we have a particularly clear picture of what we're getting at here. At one point he does seem to offer something else that could assist in clarifying how we might determine if a particular characteristic is socially salient: stereotyping. ${ }^{55}$ Again, this reliance on stereotyping, as well as the use of other examples that focus on how certain personal characteristics affect social interactions in a distinctly negative manner (being gay in a homophobic society for

52. LipPeRt-RASMussen, supra note 13 , at 31.

53. Id. at 31 n.50.

54. Id. at 31 n.50; see also Lippert-Rasmussen, supra note 13, at 169.

55. LipPeRT-RASMussen, supra note 13, at 31. 
example) are at odds with Lippert-Rasmussen's aim of presenting a nonmoralized account of discrimination. This is particularly evident when one notes that his explanation for why we should use social salience to describe discrimination relies on the fact that "almost all groups on whose behalf the charge of being discriminated against is voiced are socially salient groups. ${ }^{56}$ As Tomlin notes however, people only level a "charge" of discrimination when they feel they have been wrongfully discriminated against. ${ }^{57}$ It seems odd to have a conception of discrimination that is premised on social salience, stereotyping, and instances where individuals who are treated less favorably on the basis of these characteristics have (or at least feel they have) been wronged, and then to argue that there will be times when it is acceptable to treat someone less favorably on the basis of those characteristics.

So, Lippert-Rasmussen hasn't quite presented us with the neutral conception of discrimination he promises. This is unsurprising: discrimination qua discrimination is best understood as a form of action that is, in itself, morally neutral, and that carries no particular connection to socially salient groups at all. Eidelson's account described above should be preferred. What distinguishes discrimination from mere differential treatment is its special explanatory connection to some differential ascription of a property to those discriminated against. ${ }^{58}$ Any attempt to move beyond that neutral conception must inevitably embrace a normative grounding that explains either why discrimination is wrongful when it is wrongful or why it is legally prohibited when it is legally prohibited.

This loss of neutrality is not to be lamented, however. The legal prohibition of conduct in a liberal democracy can only be legitimated if one takes a stand on the permissibility or impermissibility of certain forms of conduct. Given that the task before us is to present an account of wrongful, legally prohibited discrimination, it is perfectly fine for us to rely on a conception of social salience that is moralized and that draws on aspects of social salience that are distinctly moral in nature. Lippert-Rasmussen's account is highly valuable and illuminates the central importance that social salience must play within our identification of the grounds for unlawful discrimination. My suggestion in this article is that a modified version of this account can be illuminating for our purposes. What matters is not social salience in the abstract but a particular kind of social salience that expresses what I will refer to as inequality-laden attitudes against some (or even all) cognate groups.

Attitudes give us reasons to deliberate and act in certain ways: " $[t] \mathrm{o}$ express an attitude through action is to act on the reasons that attitude

56. Id. at 33 .

57. Patrick Tomlin, Born Free and Equal? A Philosophical Inquiry into the Nature of Discrimination, Written by Kasper Lippert-Rasmussen, 14 J. Moral PHIL. 479 (2017).

58. Eidelson, supra note 19, at 1. 
gives us." ${ }^{59}$ An inequality-laden attitude is therefore one that is informed by a failure to treat persons as moral equals. This failure amounts to a profound instance of disrespect for the moral status of persons by failing to recognize and afford appropriate weight to the equal dignity of persons. ${ }^{60}$ Attitudes should not be confused with motives or judgements, however. Holding certain attitudes affects the kinds of decisions one might make even if there is no conscious belief one way or the other. ${ }^{61}$ As Eidelson notes, "[s]chematically, respect and disrespect for persons are states of mind that consist in taking (or failing to take) certain considerations as reasons for or against certain actions." ${ }^{\text {"S2 }}$ Similarly, Raz argues that "respecting people is . . neither a feeling, nor an emotion, nor a belief . . It is a way of conducting oneself, and more indirectly, of being disposed to conduct oneself towards the object of respect." ${ }^{63}$ In contemporary parlance, we might refer to a lack of respect as corresponding to the presence of unconscious bias wherein one is attitudinally predisposed toward treating some people as inferiors to others even if one is unaware of this. It is for this reason that it is not necessary for discriminators to have made any conscious judgement about the unequal moral worth of persons, only that they act in a way that expresses disrespect by, for example, refusing to hire a woman for fear that she will take maternity leave. This disrespect may be informed by stereotypes or other views that do not consciously manifest a feeling or belief that particular groups are inferior, but that nevertheless manifest the attitude that they are by failing to properly show them the respect they are due.

It is for this reason that Hellman, relying on a moralized conception of discrimination, urges us to recognize the "conventional and social nature of wrongful discrimination." 64 To her, the personal characteristics that we have-our traits-are morally inert in themselves; "[w] hat matters about them is their social significance in particular contexts." ${ }^{25}$ Mirroring Lippert-Rasmussen's point concerning the two scalar dimensions of social salience, Hellman argues that separating students by their last names during a school assembly "feels quite different" from separating them by race, indicating that race is more salient than the first letter of one's last name. Equally, the same trait can take on greater or lesser significance depending on the context in which it appears: "A sign that says 'men only' looks very different on a bathroom door than on a courthouse door." 66 As such, a trait is socially salient arguably when it affects social

59. Id. at 78; see also Elizabeth Anderson \& Richard Pildes, Expressive Theories of Law: A General Restatement, 148 U. PA. L. Rev. 1503, 1509-1511 (2000).

60. Eidelson, supra note 19, at 79 .

61. Id. at 78-79.

62. Id. at 79 .

63. Joseph Raz, Value, Respect, and Attachment (2001), at 138.

64. Hellman, supra note 14 , at 7.

65. Id. at 7 .

66. City of Cleburne v. Cleburne Living Ctr., 473 U.S. 432, 468-469 (1985) 
interactions in a morally charged way. This may correspond with undue negative or undue positive treatment such that, for example, race is socially salient because it corresponds with a prevalence of attitudes that afford differing levels of respect depending on the race of the individual or group in question. It is therefore not possible for blackness to be socially salient and whiteness not to be. The ground becomes salient in its universal order, even if inequality-laden attitudes typically only correspond with certain cognate groups. But typical though this disparity may be, it is not necessarily the case. We can think of societies such as Northern Ireland where inequalityladen attitudes attach to most if not all religious groups and religion carries with it undue negative treatment for out-group interactions and undue positive treatment for in-group interactions in all contexts.

Given the social salience of, for example, race, if one were to disadvantage a person or group because of their race, this would likely express the view that the interests of this person or group are of lesser importance than the interests of another comparably situated person or group that does not share that characteristic. Failing to afford equal weight to the interests of persons whose interests should be afforded equal weight fails to treat them as equals. Often this less favorable treatment corresponds with actually giving these interests less weight, as is the case when the state enacts racially specific criminal offenses or denies women the right to vote. However, in cases where one does not actually discount interests but instead allows an overriding concern relating to, for example, the maximization of profits to justify treating black applicants less favorably, an inequality-laden attitude may still be expressed. Given that treating black applicants less favorably than white applicants implies that one has given their interests less weight, the act of allowing an overriding interest to justify such treatment may itself express the attitude that it is permissible to imply that the interests of black applicants can be discounted if the justification is particularly strong. Whether this implication obtains will depend as much on the salience of a particular context as it will on the salience of a characteristic generally. ${ }^{67}$ As such, a determination that a personal characteristic is socially salient is context dependent in the two ways identified by both Lippert-Rasmussen and Hellman.

I wish to suggest in this article that the social salience that matters for a legal principle of nondiscrimination relates to personal characteristics that impact social interactions in a way that tends to express sentiments of differential moral worth, informed by biases, stereotypes, or other inequality-

67. Thus, race is likely to be socially salient in most contexts. However, we can see race used in certain employment situations (hiring a white actor to play a white Irish character for example) without this context giving rise to an inequality-laden attitude or being socially salient in the same way that it would be if an employer stipulated that they wished to hire a white applicant for reasons that were not intrinsic to the job in question. See Peter Singer, Is Racial Discrimination Arbitrary?, 8 MORAL MATTERs 185 (1978). 
laden attitudes. ${ }^{68}$ This is distinct from the broader point that the act of wrongfully discriminating amounts to an expression of these sentiments. There is an important distinction between the reasons one might have for prohibiting discrimination on the basis of particular grounds and the reasons why discrimination on the basis of those grounds is wrongful. The primary concern for the identification of grounds of discrimination is the prevalence of these attitudes, even if it is also true that most acts of prohibited discrimination will actually express such an attitude in the act itself. As such, discrimination is both informed by and likely to exacerbate the prevalence of inequality-laden attitudes. Less favorable treatment on the basis of a characteristic that is socially salient in this manner is therefore likely to be wrongful even if such views are not in the mind of the discriminator, if the discriminator is motivated by benign or prudential reasoning, or if the treatment in question ultimately does not result in harm. Furthermore, one leads to the other: the act of treating someone less favorably on the basis of a personal characteristic that is socially salient, as I have defined it, itself expresses an inequality-laden attitude. Thus, the greater the prevalence of a particular form of discrimination, the more socially salient the characteristic becomes. It is for this reason that race and sex and sexual orientation are protected grounds but hair color or support for a particular sports team are not. While some people may hold the attitude or even the belief that persons with red hair or supporters of a particular football team are morally inferior, these attitudes are not sufficiently prevalent to warrant legal intervention.

Additionally, while it is entirely possible to wrongfully discriminate against members of majority groups by, for example, creating criminal offenses specific to men or denying white employees access to the cafeteria, the consequences are likely to be worse when an inequality-laden attitude is expressed by disadvantageous treatment of members of minority groups-what Hellman refers to as those with traits that have "a history of mistreatment or current social disadvantage." ${ }^{69}$ This is because the act of discriminating against members of these groups is likely to perpetuate certain inequality-laden attitudes and to compound the injustice already faced by these persons. ${ }^{70}$ To reiterate a point made above, however, while consequences such as these are evidently salient in this context, the wrong of discrimination is in the act itself and is therefore not reducible to consequences. Wrongful discrimination against members of majority groups will express disrespect in much the same way as it would when levied

68. See Larry Alexander, What Makes Wrongful Discrimination Wrong? Biases, Preferences, Stereotypes, and Proxies, 141 U. PA. L. Rev. 149 (1992). Cf. Lippert-Rasmussen, supra note 13, at $178-184$.

69. Hellman, supra note 14 , at 21-22.

70. See Deborah Hellman, Indirect Discrimination and the Duty to Avoid Compounding Injustice, in Foundations of Indirect Discrimination Law 105 (Hugh Collins \& Tarunabh Khaitan eds., 2018). 
against members of minority groups. The difference is that it is far more likely to occur against members of minority groups and, when it does, to cause greater harm at the systemic level. Asymmetric protection will be explored in greater detail below.

Finally, a brief note on stereotypes is warranted, given that LippertRasmussen mentions them while discussing social salience. Not every action motivated by a stereotype expresses an inequality-laden attitude, even if it may be arbitrary or fail to treat those affected as autonomous individuals. Eidelson relies on two examples where persons have been treated differently on the basis of group generalizations to elucidate this point: ${ }^{71}$

The Discounted Performance. Sally, who is of East Asian descent, auditions for her school orchestra. Sally plays the violin, but not seriously, and she is not particularly talented. Kevin, the orchestra director, thinks Sally performed poorly at her audition. But Kevin figures that Sally is probably a dedicated musician who just had a bad day, and selects her for the orchestra anyway. Kevin would not have made this assumption or selected Sally if not for her ethnicity and her sex. ${ }^{72}$

The Imputed Preference. Mark, who is black, is a young associate at a law firm. The firm has a wine tasting club and a basketball team. Mark's résumé noted that he was a member of his law school's wine tasting club, and mentioned no sports. Mark's firm mentor, Jane, reviewed the résumé before taking Mark out to a get-to-know-you lunch. At the lunch, Jane makes a point of mentioning the basketball team to Mark, and neglects to mention the wine tasting club. If Mark were white, Jane would have mentioned the wine tasting club and not basketball. ${ }^{73}$

In these examples, persons have not been treated less favorably, nor have they been harmed in a nontrivial way (indeed, Sally has actually benefited from the reliance on stereotypes).${ }^{74}$ Nevertheless, both Sally and Mark have been wronged in that they have not been treated as individuals. Eidelson argues that this amounts to a failure to properly respect their moral status as autonomous individuals by judging them on the basis of their membership within a particular social group rather than their unique personal characteristics. ${ }^{75} \mathrm{He}$ is right to stress that this, in and of itself, does not amount to an expression of an inequality-laden attitude or a failure to afford equal

71. Eidelson generally avoids using the term "stereotype" as it can carry with it more connotations than he wishes to express in his discussion. Benjamin Eidelson, Treating People as Individuals, in Philosophical Foundations of Indirect Discrimination 203, 206 n.7 (Deborah Hellman \& Sophia Moreau eds., 2013). Nevertheless, he does note that there are a number of similarities between his concept of group generalization and some philosophical work on stereotyping. See, e.g., Lawrence Blum, Stereotypes and Stereotyping: A Moral Analysis, 33 PHIL. PAPERS 251 (2004).

72. Eidelson, supra note 71, at 205.

73. $I d$. at 205-206.

74. Id. at 207.

75. Id. at 209-220; see also Singer, supra note 67, at 194-195. 
weight to interests. ${ }^{76}$ Should Sally or Mark object to this conduct, they are very unlikely to complain that they have not been treated as equals; it is the fact that they have not been treated as individuals that Eidelson sees as the distinctive respect claim in these contexts. ${ }^{77}$ Equally, Singer stresses that "to be judged merely as a member of a group when it is one's individual qualities on which the verdict should be given is to be treated as less than the unique individual that we see ourselves as." ${ }^{78}$ In such cases, he argues that we may be wronged even if we ultimately benefit: being promoted over a more qualified candidate because we went to the "right" private school gives one a benefit that is "less welcome than it would be if it has been merited by our own attributes." 79 When this occurs, we may not have been treated as less than equal, but we have nevertheless been wronged. However, this conduct could amount to a failure to treat people as equals should one treat some as individuals but fail to do the same for others. ${ }^{80}$ Indeed, this is one reason why racial profiling may be wrongful. ${ }^{81}$

Furthermore, many stereotypes do not express an inequality-laden attitude. The belief that Sally will be a good musician is based on a group generalization that, if anything, views her as superior in some contexts (although possibly not morally superior). Only stereotypes that are informed by some level of negative bias express inequality-laden attitudes. Although a significantly high prevalence of generalizations made about a group of people, be they positive or negative, might indicate a failure to view members of that group as autonomous individuals and thus a failure to equally respect their individuality. Stereotypes are thus likely to be proxies for inequalityladen attitudes or to actually be expressive of inequality-laden attitudes, even if they are not always. In addition to this, a reliance on stereotypes and group generalization as a difference maker necessarily fails to respect persons as autonomous individuals even if it does not always entail or express a belief in the moral inferiority of persons.

The act of failing to treat persons as individuals is also arbitrary in many contexts. Eidelson is correct to stress that the wrong of failing to treat persons as individuals cannot be reduced to mere failures of "epistemic conscientiousness." ${ }^{22}$ Still, in cases where someone has been wrongfully judged on the basis of a group generalization, there has certainly been a failure of some kind. Although it is telling that treating someone more favorably on the basis of such generalizations is generally not enough to ground a legal challenge in the private sphere, even if there has been a moral failing.

76. Eidelson, supra note 71, at 207.

77. Id. at 208.

78. Singer, supra note 67 , at 195.

79. Id. at 195 .

80. Eidelson, supra note 71, at 208 n.12.

81. Eidelson, supra note 19 , at 174.

82. Eidelson, supra note 71, at 206. Cf. T.M. Scanlon, Moral Dimensions: Permissibility, Meaning, Blame (2008), at 70; Richard J. Arneson, What Is Wrongful Discrimination?, 43 SAN Diego L. Rev. 775, 788 (2006). 
Again, we can see a separation between the reasons why certain forms of discrimination may be wrongful and the reasons for their legal prohibition when they are legally prohibited. So, the wrong of failing to treat persons as individuals does appear to be connected to prohibited discrimination, even if the act in isolation does not necessarily amount to unlawful discrimination.

There is an important distinction between the reasons one might have for prohibiting discrimination on the basis of particular grounds and the reasons why discrimination on the basis of those grounds may be wrongful. We can see from the above that discrimination against majority groups may be wrongful even where there is not a prevalence of inequality-laden attitudes relating to, for example, heterosexuals. This can explain why there is a symmetry in protection even if the reasons motivating the protection of certain grounds are informed by the prevalence of attitudes that primarily concern minority groups. Indeed, this understanding helps us to explain why, even though it may be worse to discriminate against Muslims, discriminating against Christians is nevertheless wrongful and prohibited at law. It is the social salience of a particular trait that informs its protection as a ground for discrimination and that salience is informed by the prevalence of attitudes that far more often single out members of minority groups as inferiors, even if protection is afforded symmetrically by virtue of the wrongness of discriminating against members of majority groups. Discriminating against Christians in a Christian majority society may not be as bad as discriminating against a religious minority, but it is still wrongful by virtue of the disrespect shown and prohibited by virtue of the social salience of religion, where an aspect of that social salience is the prevalence of inequality-laden attitudes relating to some if not all religious groups.

\section{Moral Irrelevance}

There may be socially salient personal characteristics that do not qualify as grounds of discrimination specifically because those characteristics are morally or normatively relevant. In some situations, it is entirely permissible to treat someone less favorably on the basis of personal characteristics. Examples include an individual's status as a murderer, a sex offender, or even more trivial but no less salient traits such as the fact that someone is a bigot or an adulterer. These personal characteristics are arguably socially salient in the sense that they frequently carry with them connotations of moral inferiority, bias, and, in some cases, hatred. They also, to use Lippert-Rasmussen's terminology, impact social interactions in a wide variety of social contexts. It is only where differences in socially salient personal characteristics "should not affect how successful our lives are" that it is impermissible to treat someone less favorably on the basis of such traits. ${ }^{83}$

83. Khaitan, supra note 10 , at 56 . 
This does not mean that murderers, sex offenders, and adulterers are inferiors or that they should necessarily be hated; but it is perfectly permissible to treat someone less favorably on the basis of socially salient personal characteristics where those characteristics are both morally and prudentially relevant in the sense that they evidently should affect how successful our lives are. Treating someone less favorably on the basis of their race, their sex, or their sexual orientation would be perfectly permissible if differences in race or sex or sexual orientation were actually morally relevant and did, in fact, impact one's moral status. The moral irrelevance of these characteristics is necessary for the wrongness of unlawful discrimination to be established. In contrast, treating someone less favorably on the basis of their criminality or their level of honesty is often both relevant and morally acceptable.

The notion of moral irrelevance can also be used to explain not just why certain grounds are protected, but also why there might be legitimate exceptions made to the norms of nondiscrimination. This is because moral irrelevance does not equate to factual irrelevance. As Singer notes, there are many times when characteristics such as race are relevant on a factual level. ${ }^{84}$ For example, it may be relevant to discriminate on the basis of race in the hiring of an actor to play a white or black character. It may also be relevant to discriminate on the basis of race in circumstances where an employer is concerned that their racist customers will refuse to patronize a store staffed by black employees. In this instance, it is difficult to say that race is not relevant to the decision that the employer is making, since the race of employees may have a direct impact on profits. Indeed, this may even be normatively relevant if by normative we mean prudentially relevant as opposed to morally relevant. If the goal is to maximize profits, then the employer should refuse to hire black employees or women under a certain age. However, Singer stresses that it may still be wrongful to discriminate even if race is factually relevant. ${ }^{85}$ This is because race is ultimately irrelevant when it comes to weighing the interests of individuals: when we accept the principle of equal consideration of interests, it becomes arbitrary to afford greater weight to the interests of whites over blacks or vice versa. ${ }^{86}$ What matters in such instances is whether there are moral reasons that can explain why it is wrongful to racially discriminate, even when there are factual or prudential reasons to discriminate on the basis of race.

Within a liberal society it is generally accepted that arbitrariness alone is not enough to render the conduct of private actors unlawful. Gardner argues that irrationality as such wrongs nobody, except perhaps ourselves, because "we owe nobody. . . an across-the-board duty to be rational." ${ }^{87}$

84. Singer, supra note 67 , at $186-190$.

85. Id. at 187; see also Gardner, supra note 20, at 168-169.

86. Singer, supra note 67 , at 197-202.

87. Gardner, supra note 20, at 168. 
But we may owe duties not to act in a manner that is morally arbitrary such that we fail to treat others with appropriate respect. The distinction between refusing to employ liars and charlatans and refusing to employ people of a particular ethnic or sexual group is that "being black or a woman ... reflects badly on no one. Those who tend to think that it does reflect badly are gripped by irrationality." ${ }^{88}$ But this kind of irrationality is not simply a form of factual irrationality; it is a deep and profound moral failing that can justify legal intervention in certain contexts. The distinction between acts that are factually arbitrary and those that are morally arbitrary is central to understanding why racial discrimination on the basis of factually relevant but morally irrelevant considerations is prohibited. What distinguishes the actor example from the store employee example is that in one instance, accounting for the factual relevance of race and then discriminating on the basis of race does not amount to treating any person as an inferior, whereas accounting for the racist attitudes of customers and treating a potential employee less favorably because of that places the views of racists and a desire for profits above the dignity of the potential employee. ${ }^{89}$ In one instance reliance on the factual difference is morally irrelevant; in the other, reliance manifests an inequality-laden attitude and treats a member of a protected group as an inferior by failing to adequately respect them.

It is partially for this reason that disability discrimination is treated differently within most discrimination law frameworks. ${ }^{90}$ While disability qualifies as a ground for discrimination because it is a morally irrelevant personal characteristic that carries with it a prevalence of inequality-laden attitudes and biases, there are generally more instances of circumstances where disability becomes factually relevant and where this factual relevance has an impact on what ought to be done all things considered. For example, it is not wrongful to refuse to hire the blind as pilots or truck drivers. ${ }^{91}$ Legal frameworks generally respond to this by including a general exception to disability discrimination that can be justified in this manner, whereas for other grounds such as race or sex, the law sets out a list of narrowly tailored exceptions to cover those rarer instances where sex or race becomes relevant in an all-things-considered manner. One way to explain this is to note that, while disability is morally irrelevant and therefore has no impact on moral equality or how successful one's life should be, in certain circumstances it becomes normatively relevant in that it would be both morally and prudentially required to discriminate on the basis of it. Not only is hiring a blind person as a pilot simply prudentially irrational, but it is also morally wrong to endanger the lives of passengers and staff in this manner. In

88. Id. at 168 .

89. EIDELSON, supra note 19 , at 79.

90. See David Wasserman, Is Disability Discrimination Different?, in Philosophical Foundations of Discrimination Law 269 (Deborah Hellman \& Sophia Moreau eds., 2013).

91. Alexander, supra note 68 , at 151. 
such instances, it is generally lawful and morally permissible to discriminate on the basis of disability, even if disability is usually a morally irrelevant characteristic.

We can see from the above two sections that there is a degree of nuance when it comes to how certain characteristics are treated even though they have been recognized as protected grounds under the law. While grounds must relate to personal characteristics that are generally morally irrelevant and socially salient qua inequality-laden attitudes before they will be protected at all, this does not mean that all characteristics that meet those criteria will be protected in all contexts, even when dealing with the same kind of dutybearer. These features are necessary, and I would argue, jointly sufficient for the recognition of a ground of discrimination that should be prohibited at law. However, once a ground has been recognized, there still remain important questions relating to the scope and degree of protection, including whether there are good moral reasons to protect both the majority and the minority group from wrongful discrimination on the basis of the ground in question. Some of those questions can be answered by reference to these features themselves, as with explaining why exceptions are made for direct discrimination on the basis of disability. However, other questions such as the choice of duty-bearer remain open and this article does not purport to resolve them. It is sufficient for our purposes to note that the identification of grounds is closely related to the reasons why certain forms of discrimination are prohibited or permitted at law, even when we are dealing with nuanced questions having already established the protected grounds themselves.

\section{CONTINGENT BUT NOT NECESSARY FEATURES}

Drawing the previous section together, we can define unlawful discrimination generally as follows:

Unlawful discrimination occurs where a duty-bearer treats someone less favorably on the basis of a (generally) morally irrelevant personal characteristic that is socially salient in that there is a prevalence of inequality-laden attitudes relating to it.

There are, however, several other features that are often said to be necessary for the establishment of a ground of unlawful discrimination. These are, properly understood, contingent features that frequently coincide with grounds for discrimination but do not necessarily do so.

\section{A. Immutability and Fundamental Personal Identity}

It is sometimes argued, in contrast to the social salience argument advanced above, that the immutability of certain personal characteristics or the fact that those characteristics amount to a fundamental choice can explain 
the choice of grounds. ${ }^{92}$ This is particularly true in the US context, where equal protection jurisprudence operates with an open-ended list of protected grounds. Immutability was once seen as exceptionally important for triggering heightened judicial scrutiny. ${ }^{93}$ However, in the last quarter century, the concept of immutability has faced continued criticism as a method of explaining precisely why it is that certain personal characteristics are protected, and others are not. ${ }^{94}$ In particular, the concept has been critiqued for being "both over- and underinclusive." ${ }^{95}$ For example, Clarke notes that it is permissible to treat someone less favorably on the basis of intelligence, which some argue is innate, but not on the basis of religion, which can be changed ${ }^{96}$ In addition, some scholars have critiqued the very idea of immutability, arguing that it essentializes certain characteristics and presumes that they are and have been constant through time and across cultures, regardless of how particular cultures perceive or treat those characteristics. ${ }^{97}$

\section{Strict Immutability}

Leaving aside the postmodern critique, we can return to the claim that an immutability standard, in what we might refer to as the "strict" sense, suffers from problems of both over- and underinclusivity. Strict immutability standards focus on personal characteristics that cannot be changed, that arise from an "accident of birth," or that an individual is not responsible for. ${ }^{98}$ Immutability, on this definition, is clearly not sufficient to establish a personal characteristic as a ground for discrimination. There are many immutable characteristics, such as hair color and height, that do not qualify as grounds of discrimination even though they are generally morally irrelevant. It is here where the distinction between arbitrariness and unlawful

92. See Robert Wintemute, Sexual Orientation and Human Rights: The United States Constitution, the European Convention, and the Canadian Charter (1995).

93. For example, in Frontiero v. Richardson, 411 U.S. 677, 686 (1973), sex discrimination was held to warrant heightened judicial scrutiny partially because "sex, like race and national origin, is an immutable characteristic determined solely by the accident of birth." See also Hohider v. United Parcel Service, Inc., 574 F.3d 169, 190 (3d Cir. 2009) (asserting that Title VII "protects all individuals from discrimination motivated by the immutable characteristics specified in the statute”); Willingham v. Macon Telegraph Publishing Co., 507 F.2d 1084, 1091 (5th Cir. 1975) (holding that "[e]qual employment opportunity may be secured only when employers are barred from discriminating against employees on the basis of immutable characteristics, such as race and national origin") (emphasis omitted).

94. See Janet E. Halley, Sexual Orientation and the Politics of Biology: A Critique of the Argument from Immutability, 46 Stan. L. Rev. 503, 510 (1994); Kenji Yoshino, Assimilationist Bias in Equal Protection: The Visibility Presumption and the Case of "Don't Ask, Don't Tell", 108 Yale L.J. 485, 518 (1998); E. Garry Spitko, A Biologic Argument for Gay Essentialism-Determinism: Implications for Equal Protection and Substantive Due Process, 18 U. Haw. L. Rev. 571, 598 (1996).

95. Yoshino, supra note 94, at 504.

96. Jessica A. Clarke, Against Immutability, 125 YAle L. J. 2, 4 (2015).

97. Edward Stein, Conclusion: The Essentials of Constructionism and the Construction of Essentialism, in Forms of Desire: Sexual Orientation and the Social Constructionist Controversy 325, 326 (Edward Stein ed., 1992).

98. Clarke, supra note 96, at 13; see also Richard Thompson Ford, Bias in the Air: Rethinking Employment Discrimination Law, 66 Stan. L. Rev. 1381, 1418-1419 (2014). 
discrimination may be of use once more: disadvantageous treatment afforded on the basis of some immutable personal characteristics, such as hair color, will almost always be arbitrary-but that, absent social salience pertaining to inequality-laden attitudes, does not render it unlawfully discriminatory, except when assessing the lawfulness of administrative conduct through judicial review. ${ }^{99}$

Given that there is considerable overlap between unlawful discrimination and arbitrariness, grounds for discrimination will often also be irrelevant for certain decisions, particularly governmental decisions or those within the context of employment or the sale of goods and provision of services. ${ }^{100}$ Nevertheless, one can identify a ground for unlawful discrimination qua unlawful discrimination by hypothesizing circumstances where there may be good reasons to treat someone less favorably on the basis of the proposed ground. In circumstances where it is generally impermissible to treat someone less favorably based on a particular personal characteristic, notwithstanding the presence of relevant or pertinent reasons to do so, such a characteristic is likely to be a ground for discrimination. Thus, we can identify certain immutable characteristics that are often associated with arbitrary decision making that do not qualify as grounds of discrimination. Prime examples include strength and intelligence: we do not consider it to be wrongfully-let alone unlawfully-discriminatory to treat people less favorably on the basis of these characteristics when we have good reasons to justify the treatment. As such, strength requirements for employment in the fire service are not discriminatory so long as there can be shown a clear connection between the need for a strength requirement and the efficacy of the fire service as a whole. ${ }^{101}$ Equally, as mentioned above, it is not wrongful to refuse to hire the blind as pilots or the illiterate as journalists.

Immutability in the strict sense is evidently overinclusive. However, overinclusivity is not necessarily problematic unless one wishes to argue that immutability is the sole criterion for identifying grounds of discrimination. It is entirely possible that immutability is a necessary feature of protected grounds but that additional criteria are needed to fully describe the existence conditions for a ground. This being the case, problems of underinclusivity are far more important for our purposes. Ultimately, strict immutability, by focusing on personal characteristics that cannot be changed, fails to account for characteristics that evidently could be changed (even if we think one should not be forced to change) such as religious or other belief. In addition, many characteristics that were previously

99. See Associated Provincial Picture Houses v. Wednesbury Corp. [1948] 1 KB 223.

100. For example, Fullilove v. Klutznick, 448 U.S. 448, 496 (1980) ("Racial classifications must be assessed under the most stringent level of review because immutable characteristics, which bear no relation to individual merit or need, are irrelevant to almost every governmental decision.").

101. They would not even amount to indirect discrimination on the basis of sex for this reason. 
considered to be immutable appear now to be more fluid: examples include gender, arguably sex, and more controversially but still plausibly, sexual orientation and race. ${ }^{102}$ As a result, it has become clear that strict immutability standards are not necessary for the identification of grounds of unlawful discrimination. Nevertheless, there have been some recent developments that favor a revised, constructed conception of immutability.

\section{Constructed Immutability}

Reliance on a strict immutability standard has resulted in considerable time and ink being devoted to determining whether certain personal characteristics such as sexual orientation are innate or unchanging as this is seemingly the only way that they might qualify as protected grounds. This has led some advocates to reject immutability as an appropriate standard precisely because it politicizes and emphasizes the importance of biological explanations of sexuality. ${ }^{103}$ In response to this, some courts have accepted the immutability of sexual orientation, ${ }^{104}$ while others have begun to adopt a different conception of immutability, one that asks "not whether a characteristic is strictly unchangeable, but whether the characteristic is a core trait or condition that one cannot or should not be required to abandon." 105

This approach incorporates conceptions of fundamental identity or fundamental choice into the notion of immutability: "'immutability' may describe those traits that are so central to a person's identity that it would be abhorrent for government to penalize a person for refusing to change them, regardless of how easy that change might be physically." 106 On this approach, it is much easier to account for sexual orientation discrimination because "sexual orientation and sexual identity are immutable; they are so fundamental to one's identity that a person should not be required to abandon them." 107 This revised conception of immutability has breathed new

102. Many of these conclusions can be found within feminist and critical race theory. See Judith Butler, Gender Trouble: Feminism and the Subversion of Identity (10th anniversary ed., 1999), at 10-11 ("[i]f the immutable character of sex is contested, perhaps it was always already gender, with the consequence that the distinction between sex and gender turns out to be no distinction at all"); see also Appiah Anthony, The Uncompleted Argument: Du Bois and the Illusion of Race, 12 Critical Inguiry 21 (1985); Maya Sen \& Omar Wasow, Race as a Bundle of Sticks: Designs that Estimate Effects of Seemingly Immutable Characteristics, 19 Ann. Rev. PoL. Sci. 499 (2016).

103. Halley, supra note 94.

104. Thus, in Obergefell v. Hodges, the US Supreme Court observed that "[o]nly in more recent years have psychiatrists and others recognized that sexual orientation is both a normal expression of human sexuality and immutable." 135 S. Ct. 2584, 2596 (2015).

105. Obergefell v. Wymyslo, 962 F. Supp. 2d 968, 990 (S.D. Ohio 2013).

106. Watkins v. U.S. Army, 875 F.2d 699, 726 (9th Cir. 1988); see also Latta v. Otter, 771 F.3d 456, 464 n.4 (9th Cir. 2014); Whitewood v. Wolf, 992 F. Supp. 2d 410, 429 (M.D. Pa. 2014); Love v. Beshear, 989 F. Supp. 2d 536, 546 (W.D. Ky. 2014).

107. Hernandez-Montiel v. I.N.S., 225 F.3d 1084, 1093 (9th Cir. 2000); see also Watkins v. U.S. Army, 875 F.2d 699, 726 (9th Cir. 1989) ("It is clear that by 'immutability' the [Supreme] Court has never meant strict immutability in the sense that members of the class must be physically unable to change or mask the trait defining their class ... the Supreme Court is willing to treat 
life into a concept that, at least within academic literature, had become stale, the result being a surge of scholarship advocating for an expansion of the range of protected grounds through reliance on choice- or identitybased conceptions of immutability. ${ }^{108}$ In addition, Khaitan relies on the notion of constructed or effective immutability in conjunction with relative group disadvantage to identify grounds for discrimination within his theory. $^{109}$

However, fundamental-choice-based immutability is not without its critics. In particular, Clarke has argued that one of the reasons to reject revised immutability standards is that they "have buried immutability under a notion of personhood that protects certain choices already deemed morally acceptable from discrimination." ${ }^{110}$ A similar objection is that, to the extent that constructed immutability departs from strict immutability, it does so in a manner that results in us losing what is distinctive about the immutability standard itself. If, when we wish to identify a ground for discrimination, we rely on a standard that asks whether a personal characteristic is one that people cannot or should not be forced to change, then we have stopped relying on immutability and are instead relying on moral irrelevance. If "characteristics that one should not be forced to change" simply means those characteristics that we think should be protected under a principle of nondiscrimination, then reliance on immutability in this constructed sense would beg the question.

It could be argued that personal identity and not immutability should be the guiding principle here. However, constructed immutability does not simply mean fundamental choice or fundamental personal identity: it means fundamental choices or fundamental personal identities that we deem worthy of protection under a principle of nondiscrimination. Not all personal identities, no matter how fundamental they may be to the people who hold them, are protected. Indeed, many personal identities, such as astrological star sign, trade union membership, football team support, or university alumnus status, form a more foundational aspect of some people's identities than their sex, race, or sexual orientation. Reliance on a personal identity or fundamental choice requirement has the potential to focus too much on the subjective attitudes of individual persons, potentially

a trait as effectively immutable if changing it would involve great difficulty, such as requiring a major physical change or a traumatic change of identity.").

108. See Hoffman, supra note 4, at 1531-1537; Kari Balog, Note, Equal Protection for Homosexuals: Why the Immutability Argument Is Necessary and How It Is Met, 53 CLEv. ST. L. Rev. 545 (2005); Samuel Marcosson, Constructive Immutability, 3 U. PA. J. Const. L. 646 (2001); Anna Kirkland, Victorious Transsexuals in the Courtroom: A Challenge for Feminist Legal Theory, 28 LaW \& Soc. InQuiry 1, 31 (2003); Tiffany Graham, The Shifting Doctrinal Face of Immutability, 19 VA. J. Soc. Pol'y \& L. 169, 173 (2011); Zachary Kramer, The New Sex Discrimination, 63 Duke L.J. 891, 949 (2014); Susan Schmeiser, Changing the Immutable, 41 Conn. L. Rev. 1495, 1505 (2009).

109. Khattan, supra note 10 , at 56-60. Although, as mentioned above, Khaitan appears to conflate effective immutability with normative irrelevance.

110. See in particular Clarke, supra note 96 , at 33. 
excluding from protection those who do not consider their race or sexual orientation to be fundamental to their identity. On the other hand, if a more objective standard is used, we are then faced with the problem identified by Clarke of moralizing certain choices as fundamental because they are acceptable choices, even if some would not see them as fundamental to their identity and excluding other choices or identities as not worthy of protection, even if they are fundamental to someone's identity.

It is true that many of the protected grounds can be seen as fundamental personal identities, notwithstanding the above objection, and so it could be argued that this is a necessary but not sufficient feature. Nevertheless, it seems that the real work that is being done here is not by the fact that protected grounds amount to "fundamental" choices, however we determine their fundamental nature. Rather, it is the fact that these grounds have social salience and are morally irrelevant. Indeed, the social salience and moral irrelevance of these traits can and often does contribute to those traits becoming fundamental to someone's identity such that they might be classed as fundamental choices worthy of being protected under a principle of nondiscrimination. ${ }^{111}$ This being the case, it is the social salience of the traits that is of primary importance; "fundamental" choices that are not socially salient such as the university association or support for a particular football team (excluding contexts where they do carry with them inequalityladen attitudes such as in Glasgow) will not be protected whereas morally irrelevant socially salient personal characteristics may be protected even where they do not amount to fundamental choices. ${ }^{112}$

\section{B. Relative Group Disadvantage}

Relative group disadvantage has come to form a core aspect of modern antidiscrimination law scholarship. Gardner suggests that discrimination law frameworks, particularly those relating to indirect discrimination, focus on redressing relative social disparities that exist between various social groups and reveal "institutional disadvantage." 113 A focus on redressing these disparities through transformative action is often used to ground discrimination law within a distributive justice framework. ${ }^{114}$

111. Lippert-Rasmussen, supra note 13, at 32. Cf. Iris Marion Young, Justice and the Politics of Difference (1990), at 186; DaVid Edmonds, Caste Wars: A Philosophy of Discrimination (2006), at 124; G.A. Cohen, If You're an Egalitarian, How Come You're So Rich? (2000), at 34.

112. See Lippert-Rasmussen, supra note 13, at 32-33; Benedict Anderson, Imagined Communities: Reflections on the Origin and Spread of Nationalism (1983), at 110-112.

113. Gardner, supra note 33, at 4-5; see also Christopher McCrudden, Institutional Discrimination, 2 Oxford J. Legal StUd. 303 (1982).

114. See Christopher McCrudden, Changing Notions of Discrimination, in EQuality AND Discrimination: Essays in Freedom and Justice (Stephen Guest \& Alan Milne eds., 1985); Richard H. Fallon \& Paul C. Weiler, Firefighters v. Stotts: Conflicting Models of Racial Justice, 1984 Sup. Ct. Review 1 (1984); Eidelson, supra note 19, at 6, 67-68. Cf. Michael Foran, Discrimination as an Individual Wrong, 39 OXford J. Legal Stud. 901 (2019). 
It is entirely possible, indeed likely, that many aspects of discrimination law are informed by a desire to redress group-based disadvantage. In particular, the choice of duty-bearers seems to map on quite neatly to those who are what we might describe as the keyholders to the gates of opportunity. As Gardner notes, "under modern conditions the institutionalised practices of employers and landlords control access to much of the wherewithal of life for many people, a role that brings with it heavy responsibilities even to strangers." 115 We choose to obligate employers and landlords and the providers of goods and services partly because they act as gatekeepers to opportunity for people and groups that have historically suffered from wrongful discrimination.

But this is only part of the story. While our choice of duty-bearer reflects an awareness of the importance of removing barriers to success for all victims of unlawful discrimination, it is not immediately clear that this corresponds with the necessary features for identifying a ground of discrimination. One way of explaining this is to point to the distinction between the general justifying aims of discrimination law and the more intermediate inquiry into the distributive questions relating to the allocation of rights and duties. ${ }^{116}$ Nevertheless, even with this distinction borne in mind, some maintain that relative ground disadvantage is essential for establishing a ground of discrimination. Khaitan presents the following necessary condition:

Of all groups defined by a given universal order ground (eg race), members of at least one group (eg blacks) must be significantly more likely to suffer abiding, pervasive, and substantial disadvantage than the members of at least one other cognate group (eg whites). ${ }^{117}$

Here, Khaitan introduces the helpful distinction between a ground existing in a higher universal order that applies to all individuals and a particular order ground that amounts to a specific instance of a universal order ground. As mentioned above, we all have a sex, but only some of us are female: sex is the universal order ground, female is the particular order ground. Legal frameworks virtually always protect personal grounds in their universal order, protection from sex-based discrimination, regardless of whether the claimant is male or female. Nevertheless, Khaitan argues that redressing relative group disadvantage is the raison d'être of discrimination law and, consequently, that relative group disadvantage is necessary for a personal characteristic to qualify as a protected ground. ${ }^{118}$

115. Gardner, supra note 20, at 167.

116. KhatTan, supra note 10 , at 10 .

117. Id. at 31 .

118. Id. at 41; see also Aileen McColgan, Discrimination, Equality and the Law (2014); EDMONDS, supra note 111. 
However, as O'Cinneide notes, this does not do much to explain the largely symmetrical protection that is afforded by discrimination law. ${ }^{119}$ While it is important to distinguish the reasons motivating the prohibition of discrimination and the reasons motivating the choice of grounds, they are evidently connected. Specifically, if the reasons motivating the prohibition of discrimination focus exclusively on assisting members of disadvantaged groups, there is no reason to protect characteristics in their universal order. Why have race as a ground when you could protect racial minorities without having to also protect members of advantaged groups? Khaitan argues that protection for cognate groups such as men or whites is explained by reference to "expressive salience": generally symmetrical protection expresses the need for the law to be seen to be "even-handed" in its treatment of different social groups. ${ }^{120}$

Yet, if the point and purpose of discrimination law is to reduce advantage gaps that exist between these groups, there is little need to be evenhanded: different treatment and protection is afforded because there are good reasons to warrant differentiation. In fact, offering protection for members of majority groups manifestly frustrates the reduction of advantage gaps. If there was no protection afforded to men or whites from race- or sex-based discrimination, it would be far easier to implement quota systems or other forms of affirmative action that are currently unlawful in many jurisdictions. Indeed, taken to its logical conclusion, the reduction of these gaps is most efficiently achieved through legally mandated (and thus not wrongful) discrimination against members of majority groups. And yet the law does offer protection to members of majority groups. It usually precludes these kinds of measures, even if they would be more efficient in reducing advantage gaps. There are obvious exceptions to this, notably in jurisdictions such as South Africa and Canada. Yet, even here, affirmative action is permitted as an exception to the general norm of protection for members of majority groups. If the only reason to protect majorities generally is to avoid the state looking bad and the reasons in favor of allowing discrimination against whites or men in the provision of goods, employment, and so on are themselves grounded in redistributive concerns, it seems odd to protect whites or men generally. If the raison d'être for discrimination law and the reason we protect the grounds we do is to reduce advantage gaps, there is very little reason to prevent employers from refusing to hire men as a blanket policy.

We could explain this as simply deriving from the desire for the state not to look bad. But we are then faced with the task of explaining why the state would look bad for implementing these policies. One explanation is that the law operates on the presumption that most forms of race- or sex-based

119. Colm O'Cinneide, Justifying Discrimination Law, 36 Oxford J. Legal Stud. 909, 926 (2016).

120. KhaItan, supra note 10, at 179-180. 
discrimination in the employment and commercial contexts are wrongful. While it is evidently worse when a member of a minority or disadvantaged group is discriminated against, there are good reasons to think that many forms of discrimination against members of majority groups are also wrongful. It is the wrongfulness of this conduct and not a desire to appear evenhanded that explains why the ground is presented in its universal order. O'Cinneide is thus correct to note that "the moral imperative to combat group disadvantage can only provide a partial normative foundation for discrimination law." ${ }^{21}$ It is the need to balance the desire to address disadvantage against the desire to prevent wrongful conduct that best explains the tensions running through contemporary equality law frameworks. ${ }^{122}$

Nevertheless, while it is unlikely that discrimination law can be wholly explained by reference to the desire to reduce group-based disadvantage, this does not mean that relative group disadvantage is not necessary for the identification of protected grounds. Khaitan argues that "even if the practice protects men as well as women from sex discrimination, the fact that a sexual group (women) is more likely to suffer disadvantage in our societies is a necessary trigger for sex to qualify" as a prohibited ground of discrimination. ${ }^{123} \mathrm{He}$ intentionally leaves the term disadvantage undefined so as to avoid debates concerning what disadvantage matters and to allow for disadvantage to arise without any "direct exercise of human agency (eg from natural disasters or biological causes)."124 In addition, Khaitan stresses that the relative disadvantage need only correlate with a particular characteristic; it need not be causally connected. ${ }^{125}$

Despite his desire to avoid debates relating to what counts as disadvantage, Khaitan does require the scope of disadvantage to be sufficiently broad to qualify on his account. Firstly, the advantage gap in question must be more than trivial, corresponding with a significant likelihood of suffering relative disadvantage. Secondly, the disadvantage must be abiding, pervasive, and substantial:

It must be abiding in the sense that it must be likely to manifest itself over a certain length of time... pervasive in the sense that it should not normally be limited to a single, discrete sphere of human activity ... (and) substantial in the sense that it should be likely to be more than an inconvenience. ${ }^{126}$

This account, while appealing and certainly valuable in its capture of an important aspect of equality law broadly construed, runs into a number of problems. First, as is the case with immutability, relative group

121. O'Cinneide, supra note 119, at 926.

122. See Foran, supra note 114.

123. KhatTan, supra note 10 , at 34 .

124. Id. at 34 .

125. Id. at 35 .

126. Id. at 35-36. 
disadvantage can itself suffer from a problem of overinclusiveness. There are plausibly many instances of advantage gaps existing between groups where there is no protection offered under discrimination law. A prime example is groups that are differentiated on the basis of intelligence. While there is conflicting evidence as to the correlation between extremely high IQ and advantage, it is now well established that lower-than-average intelligence correlates ${ }^{127}$ with a multitude of disadvantages including reduced life expectancy, ${ }^{128}$ higher criminality, ${ }^{129}$ increased risk of suicide, ${ }^{130}$ and lower socioeconomic success. ${ }^{131}$ This disadvantage is abiding, pervasive, and substantive. It is also not limited to those with such low intelligence that they would qualify as disabled. One cognate group, in this case those with lower-than-average intelligence but not so low as to be disabled, is significantly more likely to suffer disadvantage relative to another cognate group, in this case those with higher-than-average intelligence.

Khaitan's response to the challenge of overinclusiveness is to note that the issue here would not be best described as one of unresponsiveness on the part of the legal system. ${ }^{132}$ Yet there are good reasons to think that intelligence is not and should not be protected as a ground of discrimination such that the issue here would not be one of unresponsiveness but genuinely of overinclusiveness. In many employment and university contexts, aptitude tests are used to discriminate on the basis of both experience and intelligence. To prohibit intelligence-based discrimination in these contexts, particularly if this prohibition included indirect discrimination, would be to radically alter the economic and social structures of a given state, plausibly prohibiting anything that resembles a meritocratic system. This is not to say that such transformation is undesirable, merely that it would be radically divergent from existing discrimination law. Furthermore, it would be quite a stretch to presume that the purpose of discrimination law is partly to reduce or eliminate advantage gaps between these groups, given the radical transformation that this would require.

127. There is some evidence to suggest that this is also in some respects a causal relationship. However, this is not relevant for our purposes, as there is no suggestion from any theorist in this area that a causal relationship is required to establish a ground for discrimination. This article is not claiming that there is any link between intelligence and other protected grounds except where intelligence is so low that it would qualify as a disability.

128. See Rosalind Arden et al., The Association Between Intelligence and Lifespan Is Mostly Genetic, 45 Int'l J. Epidemiology 178 (2016); Catherine Calvin et al., Intelligence in Youth and All-Cause-Mortality: Systematic Review with Meta-Analysis, 40 InT'L J. EPIDEmiology 626 (2011); Linda S. Gottfredson \& Ian J. Deary, Intelligence Predicts Health and Longevity, but Why?, 13 Current Directions Psych. Sci. 1 (2004).

129. See James Freeman, The Relationship Between Lower Intelligence, Crime and Custodial Outcomes: A Brief Literary Review of a Vulnerable Group, 3 Vulnerable Groups \& Inclusion (2012).

130. See Nora Bittar, Daniel Falkstedt \& Alma Wallin, How Intelligence and Emotional Control Are Related to Suicidal Behavior Across the Life Course - A Register-Based Study with 38-Year Follow-Up, Psych. Medicine (forthcoming).

131. See Tarmo Strenze, Intelligence and Socioeconomic Success: A Meta-Analytic Review of Longitudinal Research, 35 InTELLIGENCE 401 (2007).

132. Khaitan, supra note 10 , at 37. 
This is especially important given Khaitan's defense of a largely symmetrical system of protection mentioned above. Intelligence-based discrimination presents a sincere problem for any account of grounds that includes relative group disadvantage as a necessary condition. This is a problem that is not faced by a social-salience-based account, given that there is little evidence to suggest that there is a prevalence of inequality-laden attitudes relating to persons with lower-than-average intelligence, once we exclude the disabled, who already qualify for protection.

However, one could respond to this critique by arguing that relative group disadvantage is a necessary but not sufficient condition for the recognition of a ground of discrimination at law. This raises a second challenge: underinclusiveness. Khaitan frames this critique by focusing on whether eye color should be recognized as a ground of discrimination. Khaitan's account precludes eye color and he anticipates some respondents challenging this. However, a more pressing challenge is identified by O'Cinneide, who argues that Khaitan's account cannot fully explain certain existing antidiscrimination norms. In particular, age- and religious-discrimination provisions do not seem to correspond to any stable or pervasive disadvantage relative to cognate groups. ${ }^{133}$ This is an empirical claim and it would take sociological evidence to demonstrate one way or the other, and so it is entirely possible that age and religion do in fact correspond with disadvantage gaps of the kind Khaitan is concerned with. Nevertheless, the underlying argument raised by O'Cinneide is that these provisions seem far more concerned with preventing wrongful forms of conduct rather than closing or reducing advantage gaps. It seems at least plausible that there is little effort put into closing advantage gaps that exist between, for example, different age groups and that the primary motivation for protecting age is to prevent wrongful treatment.

The following hypothetical scenario might shed light on why relative group disadvantage is not a necessary condition, even if it does often correspond with social salience and a prevalence of inequality-laden attitudes. Imagine a world in which the tensions that exist between Catholics and Protestants in Northern Ireland are as high as they were during the peak of the Troubles but where there is no relative group disadvantage between them. Members of each group are just as likely to be successful, just as likely to occupy positions of authority, and just as likely to suffer discrimination in their lives on the basis of their religious or political affiliation. This context would be the prime example of there being a prevalence of inequality-laden attitudes based on morally irrelevant personal characteristics and so religion or political belief would qualify as a protected characteristic on that account. $^{134}$ In contrast, Khaitan would have to conclude that religion or

133. O'Cinneide, supra note 119, at 921.

134. This argument corresponds with the work of Reva Siegal on the role of antibalkanization as an underlying justification for discrimination law. See Reva B. Siegel, From 
political belief should not be protected in this context. He could bite this bullet and do exactly that. However, this position would be so counterintuitive that it would require significant argumentation to defend. A more compelling approach would accept that religion or political belief should be protected in this context and that it is the prevalence of inequality-laden attitudes and not relative group disadvantage that is essential, even if disadvantage is contingent and often does correlate with the grounds in question.

\section{CONCLUSION}

Theorizing discrimination law requires one to carefully balance of a number of discrete but interrelated concerns. We must account for the normative underpinnings of the area of law as a whole while also paying sufficient attention to more concrete questions in relation to the scope of legal intervention, the identification of rights- and duty-bearers, and the grounds on which the law will prohibit discrimination once we have identified the pertinent areas of intervention and the appropriate actors. This article has sought to provide some conceptual and theoretical clarity regarding the question of grounds. This has inevitably also included some discussion of broader normative foundations, given the important connections that exist between these two levels of inquiry.

Drawing the above observations together, we can conclude that unlawful discrimination occurs where a duty-bearer treats someone less favorably on the basis of a (generally) morally irrelevant personal characteristic that is socially salient in that there is a prevalence of inequality-laden attitudes relating to it. Immutable personal characteristics and group disadvantage are neither necessary nor sufficient to establish a ground of unlawful discrimination. Of course, relative group disadvantage, particularly on the basis of immutable characteristics, may contribute to social salience or the prevalence of inequality-laden attitudes. However, in these contexts, it is the social salience that establishes a trait as a protected ground. It is thus very likely to be the case that most real-world contexts will demonstrate both group disadvantage and social salience. The important question that needs to be asked at that point is whether it is the group disadvantage or the social salience that prompts the protection. Which is necessary and which is merely contingent? When it comes to identifying the grounds of discrimination, it is the social salience that matters. However, when it comes to identifying duty-bearers and what constitutes a breach of duty, it is far more likely that the desire to reduce relative group disadvantage is more operative. 
So, where does that leave us with regard to the enumeration of additional grounds of discrimination? This article does not specifically address the controversies relating to discrimination on the basis of beauty, weight, or genetic identity. However, it does provide a framework for answering them, grounded in the social realities of prejudice and bias. In interpretating the "other status" element of discrimination law frameworks, a court should look to the moral irrelevance and social salience of the personal characteristic in question and ask whether there is a prevalence of inequality-laden attitudes in their society as a first port of call.

This will require empirical analysis in borderline cases, as would be the case for both relative group disadvantage and immutability. So, the court cannot make these assessments in abstraction from the wider social context within which it operates and thus must be assisted by robust sociological analysis in much the same way that it must be assisted by empirical evidence of harm when assessing a claim of negligence. Equally, judges must draw on morally engaged legal reasoning if they are to make proper sense of the moral irrelevance condition. When faced with the evolution of legal principle, either through the common law method or under the authorization of a purposely open-ended legislative enactment or international treaty, legal analysis inevitably becomes morally and socially engaged. It is hoped that this article might shed some light on how that inquiry might proceed should the courts choose to entertain the possibility of an expansion of the existing grounds. 